\title{
O PROGRAMA PRÓ-HAITI NAS UNIVERSIDADES PÚBLICAS BRASILEIRAS (2011-2016) ${ }^{1}$
}

\author{
Fritznel Alphonse ${ }^{2}$ \\ José Rivair Macedo
}

RESUMO: O presente artigo se propõe a efetuar uma análise do programa Pró-Haiti implementado nas universidades públicas brasileiras UNICAMP, UFSC, UFSCAR e UFRGS, nos anos de 2011 a 2016, no âmbito da proposição feita por vários países de possibilitar que jovens haitianos continuassem seus estudos universitários no exterior afim de fortalecer a educação superior haitiana no contexto pós-terremoto que abalou o Haiti em 2010. Analisaremos brevemente a historicidade e desenvolvimento das relações bilaterais entre Brasil e Haiti; o histórico do Pró-Haiti e suas propostas para o Haiti; a implementação e os resultados alcançados pelo Programa nas quatro Universidades parceiras. Com isso, pretende-se verificar de que modo o Brasil cumpriu essa promessa com o Haiti. As reflexões propostas buscam problematizar em que medida o Programa Pró-Haiti foi inserido como uma das promessas feitas pelo Brasil ao Haiti no período pósterremoto de 2010 do país, a fim de constatar que o Brasil não cumpriu e não vai cumprir essa promessa e que, por isso, o Brasil não estaria contribuindo para a reconstrução do Haiti por meio desse programa.

PALAVRAS-CHAVES: Relação Internacional Haiti/Brasil; MINUSTAH; Pró-Haiti apoio a Instituições de Ensino Superior Haitianas; Formação de Recursos Humanos no Haiti.

${ }^{1}$ Agradeço muito aos meus amigos brasileiros e à professora Dra. Denise Maria Cogo, da Escola Superior de Propaganda e Marketing - ESPM, pelas revisões e valiosas contribuições ao texto.

${ }^{2}$ Graduado em Educação pela Universidade Autônoma de Porto Príncipe/Haiti (2010), Mestre em Educação na Área Interdisciplinar de Ciências Sociais da Educação pela Universidade Estadual de Campinas e Doutorando e Bolsista do Programa de Excelência Acadêmica PROEX da CAPES do Programa de Pós-Graduação em História, Universidade Federal do Rio Grande do Sul. E-mail: fritznel.alphonse@ufrgs.br

${ }^{3}$ Orientador da pesquisa de doutoramento no Programa de Pós-Graduação em História -PPGHist/IFCH/UFRGS. E-mail: jrivair@uol.com.br 


\title{
THE PRO-HAITI PROGRAM IN BRAZILIAN PUBLIC UNIVERSITIES (2011- 2016)
}

\begin{abstract}
The present article intends to analyze of the program Pró-Haiti implemented in the Brazilian public universities UNICAMP, UFSC, UFSCAR and UFRGS in the years from 2011 to 2016, in the extent of the proposition done by several countries of making possible that Haitian youths continued their academical studies in the exterior in order to strengthen the Haitian superior education in the context powder-earthquake that affected Haiti in 2010. We will analyze the historicity and development of the bilateral relationships shortly between Brazil and Haiti; the report of Pró-Haiti and their proposals to Haiti; the implementation and the results reached by the Program in the four Universities partners. The proposed reflections look for to problematize in that measured the Program Pro - Haiti was inserted as one of the promises done by Brazil to Haiti in the period powderearthquake of 2010 of the parents, in order to verify that Brazil didn't accomplish and it won't accomplish that promise and that for that, Brazil would not be contributing to the reconstruction of Haiti for middle of that program.
\end{abstract}

KEYWORDS: Relationship International-Haiti/Brazil; MINUSTAH; Pro-Haiti Support to the Haitian Institution of Higher education; Formation of Human resources in Haiti.

\section{INTRODUÇÃO}

O presente artigo se propõe a efetuar uma análise do programa Pró-Haiti implementado nas universidades públicas brasileiras, como a UNICAMP, UFSC, UFSCAR e UFRGS, nos anos de 2011 a 2016, no âmbito da proposição feita por vários países de possibilitar que jovens haitianos continuassem seus estudos universitários no exterior a fim de fortalecer a educação superior haitiana no contexto pós-terremoto que abalou o Haiti no dia de 12 de janeiro de 2010. No marco desse objetivo, o Pró-Haiti visa contribuir com o processo de reconstrução do Haiti por meio do apoio à formação de recursos humanos e à reestruturação das Instituições de Ensino Superior Haitianas (IESH). Para isso, analisaremos brevemente o desenvolvimento das relações bilaterais entre Brasil e Haiti no século XXI; o histórico do Pró-Haiti e suas propostas para o Haiti; e 
a implementação e os resultados alcançados pelo Programa nas quatro Universidades parceiras acima mencionadas no período investigado. Com isso, pretende-se verificar se o Brasil cumpriu a promessa feita ao Haiti.

O sismo de magnitude de 7,3 na escala Richter que abalou a república do Haiti no dia 12 de janeiro de 2010 deixou um balanço de mais de 300.000 mortos e 300.000 feridos, entre os quais 5.000 amputados e mais de 1,5 milhões de desabrigados na região metropolitana de Porto Príncipe, além de mais de 600.000 pessoas nas regiões abaladas para se abrigar no resto do país (HAITI, 2010). ${ }^{4}$ Diante de tal quadro, as inúmeras promessas ${ }^{5}$ de ajuda feitas ao Haiti se multiplicaram de modo significativo, fomentando as expectativas de um Haiti reconstruído e recuperado - o que, no entanto, não correspondeu à realidade que passou a ser vivenciada pela sociedade haitiana.

Os primeiros migrantes não demoraram muito tempo para se espalhar pelo mundo, sobretudo em direção a destinos não habituais na história da

\footnotetext{
${ }^{4}$ Os danos materiais foram avaliados da seguinte forma: "105.000 residências foram destruídas, mais de 208.000 irreversivelmente danificadas, mais de 1.300 estabelecimentos de educação, mais de 50 hospitais e centros de saúde desabaram ou ficaram inutilizados dentre os principais estabelecimentos públicas que foram destruídos nesta tragédia". Dessa forma o valor total de danos e perdas materiais causados pelo terremoto "foi avaliado e estimado em US\$ 79.000 .000 .000 , o equivalente a $120 \%$ de produto interno bruto do país (PIBP) em 2009" (HAITI, 2010, p.7). Esses dados devem ser problematizados, já que a pesquisa nos materiais disponíveis sobre o Haiti no período pós-terremoto demonstra não haver nenhum consenso entre as agências e os autores que produziram os dados estatísticos sobre essa tragédia no que diz respeito ao número de mortos pelo terremoto, e tampouco aos amputados, desabrigados, os danos materiais, os desabamentos e o número de estabelecimentos que ficaram inutilizados nesse terremoto, o valor total de danos e perdas materiais, os deslocados para as regiões do interior e de fora do país. Mas, de qualquer forma, eles são importantes na medida em que mostram tanto o quadro de destruição material quanto de pessoas afetadas.

${ }^{5}$ Com efeito, logo após o terremoto, a propaganda em torno da reconstrução do Haiti impõe-na enquanto a mais nova e próspera indústria neste país, transformado em paraíso das Organizações não governamentais (ONGs) nos últimos três decênios. Em 1987, quando foi criada a Unité de coordination des activités d'ONG (UCAONG), o número total do conjunto de ONGs computadas no território haitiano era ainda abaixo de 1.000 (LOUIS-JUSTE, 2007, p. 106). Já em fevereiro de 2010 (um mês depois do terremoto), o então Primeiro-Ministro JeanMax Bellerive lançara a seguinte acusação contra os grandes financiadores de ONGs: "São eles que permitem que as ONGs façam o que querem. (...)” Jean Michel (2010).
} 
diáspora haitiana ${ }^{6}$ como, por exemplo o Brasil. Até novembro de 2015, o número de migrantes haitianos que tiveram seus processos deferidos no Brasil foram contabilizados em 43.871, entrando sem documentos pela fronteiras brasileiras. De acordo com dados do Governo Federal brasileiro, a maioria deles com a "ajuda" de coiotes e outros aliciadores. Estes, por sua vez, já lucraram 60 milhões de dólares com o negócio. Há que se levar em conta também aqueles migrantes que entraram de forma regular, já com visto permanente de trabalhador (SEGUY, 2015).

De acordo com os dados oficiais do Ministério dos Haitianos Residentes no Exterior (MHAVE), aproximadamente entre 4 e 5 milhões de haitianos estão espalhados pelo mundo ${ }^{7}$. Dentre as promessas de auxílio e reconstrução, o Brasil, que está presente no território haitiano desde 2004, por meio de seus exércitos, liderando ${ }^{8}$ as forças de ocupação das Nações Unidas no Haiti, por meio da MINUSTAH, e fazendo seus negócios por meio de suas ONGs, se propõe a ajudar o Haiti ainda no contexto do terremoto de 2010. Essa ajuda abrange principalmente as áreas da Educação Superior, além da saúde, por meio do "Pró-Haiti". O programa visa, antes de tudo, contribuir para a reconstrução do Haiti através do apoio à formação de recursos humanos e à reestruturação das IES haitianas, prevendo, ainda, a inclusão de outras modalidades

\footnotetext{
${ }^{6}$ A respeito da diáspora haitiana espalhada pelo mundo, cf. o livro Espace et Liberté en Haïti de Georges Anglade (1982, p. 132). Nesse livro, o geógrafo haitiano produziu um mapa para ilustrar os diferentes espaços internacionais das mobilidades haitianas. A partir desse estudo sobre a diáspora haitiana espalhada pelo mundo, o referido autor cunhou a expressão "novo espaço haitiano".

${ }^{7}$ De acordo com os dados do Congresso Mundial Haitiano (CMH) do ano de 2005, em Nova York e Nova Jersey, são estimados em 1 milhão; em Miami, 750 mil; em Boston, Chicago e Los Angeles, 150 mil; no Canadá, 120 mil; na França, 100 mil, incluindo os Departamentos Ultramar; na República Dominicana, 750 mil; em Cuba, 400 mil, e nos demais países da América Latina, 75 mil, além daqueles instalados na África e na Ásia (CAHIER no 1, p. 16, janeiro 2005).

${ }^{8}$ Dentre as Motivações brasileiras para liderar MINUSTAH no marco da Política Externa: "De um lado, condiz com as narrativas de política externa humanista e diplomacia da solidariedade construídas durante a gestão do então presidente Lula. De outro lado, responde as aspirações mais pragmáticas como a obtenção de um assento no Conselho de Segurança da ONU CSONU, possíveis ganhos econômicos indiretos e a possibilidade de aperfeiçoar a atuação de tropas nacionais" (WAISBICH \& POMEROY, 2014, p.4).
}

Temáticas, Campinas, 25, (49/50): 233-270, fev/dez. 2017 
constantes no Memorando de Entendimento (ANEXO I DA PORTARIA DO PROGRAMA, 2010).

A escolha desse tema de pesquisa tem os seguintes pontos como principais motivações: $1^{\circ}$ ) iniciar um estudo inédito sobre este convênio educacional implementado, a partir de 2011, nas quatro Universidades públicas brasileiras citadas - UNICAMP, UFSC, UFSCAR e UFRGS; $2^{\circ}$ ) oferecer informações gerais a respeito do programa, principalmente sobre os resultados alcançados no período estudado. Entende-se que a análise proposta nesta pesquisa poderá colaborar com um resgate sobre essa temática tanto no que se refere aos objetivos traçados para o estudo quanto em termos de respostas às questões norteadoras deste trabalho de pesquisa.

Nessa perspectiva, este trabalho propõe uma problematização a partir das seguintes perguntas norteadoras: quais são os objetivos e metas do PróHaiti e como se deram os processos de implementação e transformação do programa entre 2011 e 2012? Será que o Brasil conseguiu abrir mão de seus negócios pessoais (geopolíticos) para cumprir os objetivos e as metas que nortearam esse programa nas quatro Universidades escolhidas para o estudo? A partir dos posicionamentos adotados pelo Brasil na liderança da MINUSTAH no Haiti desde 2004, quais são os resultados desse programa no período de 2011-2016? Será que o Brasil conseguiu contribuir na reconstrução do Haiti por meio desse programa?

A hipótese desse trabalho é que as relações internacionais vivenciadas pelo Haiti com a Comunidade Internacional há mais de dois séculos nunca trouxeram resultado positivo para o país, que continua padecendo dos mesmos problemas sociais, políticos e econômicos. Este trabalho se constrói a partir de uma pesquisa documental operada numa perspectiva sócio-histórica e está apoiado em documentos e informações oficiais disponíveis em sites como o da CAPES e do MEC, como, por exemplo, tabelas estatísticas, e, ainda, em artigos de jornais, relatórios de avaliação, revistas, cartas, filmes, fotografias etc. publicados nos sites oficiais das universidades parceiras do Pró-Haiti. Os dados coletados foram organizados e processados, primeiro em alguns softwares, como MSWord, MSExcel etc., para serem posteriormente tratados, analisados, 
interpretados e sintetizados, de acordo com os eixos norteadores desse estudo.

\section{AS RELAÇÕES BRASIL-HAITI E A MINUSTAH}

Ainda que as relações entre Brasil e Haiti remontem no mínimo a 1928, foi somente em 1954 que o nível de representação foi elevado ao de Embaixada. Desde o ano de 1982, os dois países firmaram um Acordo Básico de Cooperação Técnica e Científica. Embora o Brasil tenha retirado seu Embaixador do Haiti, ainda assim sua Missão em funcionamento, mesmo que apenas em nível de Encarregado de Negócios (VALLER FILHO, 2007). Na primeira década do século XXI se consolidou uma nova fração da burguesia brasileira ligada ao mercado internacional não mais pela simples exportação de mercadorias, mas também pela geração de capitais na forma de investimentos diretos, implicando na recente expansão das multinacionais brasileiras. Este processo de internacionalização da burguesia brasileira coincide com os seguintes objetivos:
o aumento de conflitos envolvendo a burguesia brasileira em países da América do Sul - empresários da soja em terras paraguaias e bolivianas, Petrobrás na Bolívia e Odebrecht do Equador -, e com ii) uma orientação da política externa brasileira de maior destaque internacional, não só buscando assento no Conselho de Segurança da ONU, mas também por ventura para poder comandar as tropas da Missão das Nações Unidas para a Estabilização no Haiti desde 2004 com objetivo de ampliar sua pasta de políticas externas de cunho subimperialista na região (BUENO, SEABRA, 2009, p.1).

De acordo com Luce (2007), a política externa brasileira dos governos Lula leva traços significativos de uma política subimperialista, sobretudo no que se refere à cooperação antagônica. $\mathrm{O}$ autor destaca como 
traços principais do subimperialismo brasileiro a inserção das empresas brasileiras no cenário internacional, bem como a construção da Iniciativa para a Integração da Infraestrutura Regional Sul-Americana (IIRSA). Tal inserção é feita por empresas brasileiras que atuam em setores de baixo valor agregado, como alimentos e recursos naturais.

Com base nos marcos conceituais do subimperialismo propostos por Ruy Mauro Marini, esta etapa do capitalismo poderia ser traduzida como a expressão política e econômica da integração dos sistemas de produção dos países dependentes à etapa monopolista da economia dos centros imperialistas. Nesse sentido, o subimperialismo traduz-se também na vigência de determinadas alianças entre frações da burguesia que buscam ativamente a ampliação da influência política e do controle de mercados externos. Segundo Claudio (2009, p.28), “(...) el acierto más perdurable de los primeros teóricos del subimperialismo fue captar la transformación de las viejas burguesías nacionales, en burguesías locales".

Enquanto isso, no Haiti a situação de crise geral que perdurou no país durante os anos de 1990 teve como resultado o fato de os desdobramentos dessas crises terem ensejado uma intervenção militar dos EUA e missões da ONU no país nos anos de 1991-2004. Logo após essa intervenção, no dia de 30 de abril de 2004, a ONU criou a Missão das Nações Unidas para a Estabilização do Haiti (MINUSTAH) por meio da Resolução n.1542. $\mathrm{Na}$ época, o Brasil foi eleito para liderar essa missão por meio de setores de seu exército já presentes no Haití, tendo assumido o comando militar da MINUSTAH de junho de 2004 até outubro de 2017². O referido

\footnotetext{
${ }^{9}$ Desde o início da ocupação internacional liderada pelo Brasil, o país teve o maior contingente de tropas brasileiras. Japão, Chile, Nepal, Jordânia, Uruguai, Paraguai, Coreia do Sul, Sri Lanka, Argentina, Bolívia, Guatemala, Peru, Filipinas e Equador também enviaram tropas ao país. Durante esse período de 13 anos de ocupação do Haiti, o componente militar da MINUSTAH sempre foi liderado por comandantes brasileiros. O último oficial a exercer o cargo foi o General Ajax de Porto Pinheiros. Desde 2004, cerca de 37.500 militares brasileiros trabalharam nessa ocupação. Desde o dia 16 de outubro de 2017, a MINUSTAH foi substituída pela Missão das Nações Unidas para o apoio à Justiça no Haiti (MINUJUSTH), conforme a resolução 2.350 do conselho de Segurança. (...) A MINUJUSTH se concentrará especificamente no sistema de justiça e na polícia. De acordo com o discurso do Dr. Mamadou Diallo, vicerepresentante especial do secretário-geral da ONU no Haiti e diretor interino da nova missão, proferido no dia 16 de outubro de 2017, seu propósito seria o de aprofundar o trabalho da
} 
Acordo Básico de Cooperação Técnica e Científica existente entre Brasil e Haiti viria a entrar em vigor apenas em novembro de 2004, por meio do Decreto no. 5.284 (VALLER FILHO, 2007). Assim, o conjunto das missões técnicas ${ }^{10}$ iniciais que o Brasil mantém no Haiti resultou em um número de doze projetos, aos quais se somariam outros dois identificados posteriormente, perfazendo um total de quatorze projetos ${ }^{11}$ que deveriam ser implementados no período que ultrapassou o mês de dezembro de 2006.

A ocupação ocorrida no Haiti, a partir da Missão, foi justificada por meio da construção da falsa ideia de que o país estava em guerra e precisava ser pacificado. Durante os 13 anos de ocupação da ONU no país por meio da MINUSTAH ${ }^{12}$, dentre os muitos prejuízos que a Missão provocou para população haitiana, vale destacar que, no dia 19 de outubro de 2010, foi anunciada oficialmente a relação entre a disseminação da epidemia de cólera e a presença de soldados integrantes da Missão - o que, vale notar, ocorreu meses depois do abalo que arrasou o país. O representante da Organização dos Estados Unidos (OEA) no Haiti em 2010, o diplomata Ricardo Seitenfus, em uma entrevista ao jornal suíço Le Temps no dia 23 de dezembro de 2008 reconheceu o caso do Haiti como prova do fracasso da ajuda internacional.

MINUSTAH de forma a intensificar a segurança e fortalecer a democracia e as instituições da nação. Disponível em: https://minustah.unmissions.org/ e https://minujusth.unmissions.org. Acesso em 10/01/2018.

${ }^{10}$ Nesse contexto, os técnicos da EMBRAPA, Infraero, Ministério da Saúde, Ministério do Meio Ambiente e SENAI estiveram no Haiti em diferentes oportunidades de trabalhos nos anos de 2004 e 2005.

${ }_{11}$ As informações encontradas no site oficial da Agência de Cooperação Brasileira (ABC) mostram que, dentre os projetos elencados, onze deles já foram executados no país desde 2009, sem que tenham causado nenhum impacto positivo para a população haitiana em termos de criação de emprego, além de 3 projetos bilaterais e 5 projetos trilaterais que estão em execução no Haiti.

${ }^{12}$ É uma missão complexa, baseada no capítulo VII da Carta das Nações Unidas. Segundo o mandato, as funções da missão dividir-se-iam em três seguintes esferas: i) criação de um ambiente seguro e estável; ii) garantia do respeito aos direitos humanos; e iii) apoio ao processo político no Haiti (MORNEAU, 2006, p. 74-75). A missão deve ser entendida como uma operação de imposição da paz, envolvendo tanto missões ofensivas como ações tradicionais de manutenção da paz e de estabilização, além de distribuição de assistência humanitária. 
Em 22 de dezembro, começaram as primeiras manifestações populares exigindo a apuração de denúncias de compra de votos nas eleições haitianas de 2010 reprimidas pela MINUSTAH (SEGUY, 2014). Em 27 de dezembro de 2010, o representante da Organização dos Estados Americanos - OEA no Haiti, Ricardo Seitenfus, foi demitido por críticas feitas à ocupação e publicadas na imprensa. De acordo com um documento da Rede Nacional de Defesa dos Direitos Humanos (RNDDH, 2011), muitos agentes da MINUSTAH estiveram envolvidos "em casos de estupro, roubo, assassinato e detenções ilegais e arbitrárias", inclusive um caso de abuso e exploração sexual de menores. Vieira (2017), citando a escritora de origem haitiana Edwidge Danticat, em texto veiculado na revista americana The New Yorker publicado no dia 19 de outubro, afirma que

\begin{abstract}
(...) as tropas chegaram a subir no telhado da igreja onde seu avô era pastor para atirar nas pessoas que andavam pela vizinhança. Ela também relembra um episódio em Cité Soleil, um dos bairros mais pobres e populosos da capital haitiana, em que a MINUSTAH ${ }^{13}$ teria usado mais de 22 mil balas e 78 granadas para executar indivíduos classificados como "membros de gangues".
\end{abstract}

De acordo com Chade (2017), em Genebra houve investigações internas da ONU que revelaram que tropas brasileiras foram acusadas de abusos sexuais. Os dados foram revelados pela agência Associated Press (AP), segundo a qual as forças de paz das Nações Unidas no Haiti enfrentam denúncias de mais de 2 mil casos de abusos ${ }^{14}$, muitas vezes de menores e daqueles que deveriam ser protegidos. Nessas denúncias feitas contra os contingentes da MINUSTAH ${ }^{15}$ no Haiti, o Brasil está classificado

\footnotetext{
${ }^{13}$ Considerando assim, a MINUSTAH foi uma operação militar contínua em um país que não estava em guerra.

${ }^{14}$ Para maiores informações, ver https://conduct.unmissions.org/sea-overview. Acesso em 10 de jan. 2018.

${ }^{15}$ Agora, os soldados dessa missão já não estão mais no país, mas deixaram para trás vítimas de abuso, de exploração, crianças que nunca conhecerão seus pais e famílias inteiras que foram marcadas com o ferro vermelho da vergonha (MILFORT, 2017, tradução nossa).
} 
entre os 23 países cujos soldados são acusados de abusos sexuais enquanto serviam em missões de paz da ONU pelo mundo. A informação é da agência Associated Press e diz respeito às missões promovidas pela organização nos últimos 12 anos. As tropas brasileiras teriam praticado as violações no Haiti. Ao todo, são avaliadas mais de 2.000 denúncias, 300 delas envolvendo crianças ${ }^{16}$.

Seguy (2014) afirma, sobre a "Guerra do Haiti” ou "Missão de Paz no Haiti", que o seu país nunca precisou de missão de paz, pois nunca esteve em guerra. Lembra que, ao estar no Brasil, observou que a situação de desordem que levou à intervenção internacional no Haiti, comparada aos conflitos dentro das favelas do Rio de Janeiro, leva a concluir que, por mais que esses conflitos existam, e que justifiquem muitas coisas, não bastam para dizer que o Brasil esteja em guerra civil e precise ser pacificado (SEGUY, 2014). O autor se pergunta sobre qual foi o papel da MINUSTAH no Haiti durante todo esses 13 anos, destacando que o papel do Brasil no Haiti foi de repressor dos movimentos sociais de contestação: "um papel de policial reprimindo qualquer movimento contra esta ordem que se está caracterizando no Haiti". Para o autor, o Haiti de hoje é um país sem soberania, onde o governo nacional tem menos poder que um governador de Estado: se o Haiti fosse anexado aos EUA, seu governador teria mais autonomia que os dirigentes haitianos têm agora (SEGUY, 2014).

\section{HISTÓRICO DO PROGRAMA PRÓ-HAITI}

O Pró-Haiti é um Programa Emergencial em Educação Superior no Brasil que foi inserido como uma das promessas oferecidas ao Haiti no período pós-terremoto. Este foi formulado por meio de constatações feitas pelo governo federal brasileiro neste período, presente no Haiti desde 2004, como já referido. Como se deu a criação do Pró-Haiti? Na verdade, o Pró-Haiti foi criado por meio da Portaria No 092, que estabelece

\footnotetext{
${ }^{16}$ Cf.https:// noticias.r7.com/internacional/fotos/brasileiros-estao-entre-soldados-das-forcasde-paz-da-onu-acusados-de-abuso-sexual-no-haiti-18042017\#!/foto/1
} 
o Programa Emergencial Pró-Haiti em Educação Superior e dispõe sobre os procedimentos para operacionalização das atividades do programa, orientado pelo Memorando de Entendimento assinado pelo Brasil e Haiti no dia de 25 de fevereiro de 2010 para a reconstrução, o fortalecimento e a recomposição do Sistema de Educação Superior do Haiti. Logo depois da assinatura desse Memorando, Thomaz \& Nascimento (2012, p. 2) relatam que com grande fanfarra se anunciou que o Brasil ofereceria pelo menos 500 bolsas a estudantes da rede universitária haitiana, atingida de modo particularmente devastador pelo terremoto. Por todo o Brasil, universidades ofereceram vagas para recebê-los. Nessa época, este anúncio era crucial e motivou os estudantes a virem rapidamente, posto que suas faculdades estavam em ruínas, seus estudos paralisados e a continuidade de sua formação seria decisiva para a reconstrução do Haiti.

Nesse programa poderiam ser incluídas outras modalidades que pudessem ser consideradas pertinentes ao Programa (art. $1^{\circ}$. da portaria n.092). O Pró-Haiti concede bolsas de estudos de graduação sanduíche em universidades públicas brasileiras para os estudantes das instituições de ensino superior de Porto Príncipe, mas foram incluídos também estudantes oriundos de outras cidades do país no resultado da seleção do programa. A adesão das IES ao Programa que ofereceria vagas para os candidatos a serem selecionados seria feita exclusivamente com base em cartas-convite, por serem remetidas às mesmas instituições que participam do Programa de Estudantes de Convênio de Graduação (PEC-G) - coordenado pela Secretaria de Educação Superior (SESU) do Ministério da Educação e pelo Ministério das Relações Exteriores.

Seria dada prioridade às áreas e cursos definidos pelo relatório diagnóstico, conforme informação contida no Anexo I do Portaria n. 092 do Pró-Haiti. Quais eram as propostas do programa para o Haiti? Ele operaria principalmente em duas grandes modalidades de apoio previstas, podendo abranger, entre outras, o que se segue: a) Formação de recursos humanos em Educação Superior; b) Apoio à reestruturação das instituições de ensino superior haitianas (parágrafo único do art.1 ${ }^{\circ}$ da portaria n. 092). Este seria promovido em parceira com o Ministério das Relações Exteriores (MRE) por meio de missões de especialistas para 
realizar diagnóstico e o acompanhamento do Programa, sob o amparo do Acordo Básico de Cooperação Técnica e Científica entre Brasil e Haiti, firmado em 15 de outubro de 1982 (art. $2^{\circ}$ da portaria n.092). Os objetivos do Pró-Haiti norteiam-se pelos seguintes princípios:

Apoiar às instituições de ensino superior brasileiras na apresentação de projetos de pesquisa (...); b) Propiciar a realização de graduação sanduiche de estudantes haitianos em instituições de ensino superior brasileiras; c) Apoiar as instituições de ensino superiores brasileiras que mantêm cursos de português para estrangeiros, (...) d) Conceder bolsas de graduação e pós-graduação, (...); e) Contribuir para reestruturação das instituições de ensino superior haitiana, (...) (ANEXO I DA PORTARIA N.092, 2010, p.1).

De acordo com o Anexo I da Portaria n.192, 2010, as modalidades do programa orientam pelas seguintes diretrizes:

Apoio de projeto de diagnóstico de pesquisador, (...);2) Bolsa de graduação sanduíche, (...); 3) Apoio à reconstrução da universidade; (...); 4) Programa de Pós-Graduação especial ou PEC-PG; (...); 5) Apoio aos cursos de português para estrangeiros. (...). Analisando as modalidades estabelecidas pelo Pró-Haiti, merecendo destacar três dentro as cinco modalidades que estruturaram esse programa, vale apena de dizer que, na nossa opinião, isto não vai contribuir para nada no nosso sistema de Ensino Superior. $\mathrm{Na} 1^{\mathrm{a}}$ modalidade, tinha sido contemplada apenas os interesses pessoais do Brasil na área de pesquisa sobre o Haiti. E a $2^{\mathrm{a}}$ modalidade se enquadrou como uma política de apoio adequado para o sistema. A $3^{\text {a }}$ modalidade encontra-se enquadrada, sem dúvida, como algo complementário à primeira modalidade do programa já referida (ANEXO I, PP.1-3 DA PORTARIA N. 192, 2010). 
A continuidade do programa depende do desempenho acadêmico de estudantes beneficiados e será avaliado unicamente pelas IES brasileiras, que decidirão a cada período letivo sobre a renovação da bolsa de estudos e a permanência do estudante na instituição. No que concerne aos financiamentos do Programa, estes serão executados de acordo com a disponibilidade orçamentária ${ }^{17}$.

\begin{tabular}{|c|c|c|c|}
\hline Ben eficiários & Tipo de Auxílio & $\begin{array}{l}\text { N. de } \\
\text { meses }\end{array}$ & Valor Unitário \\
\hline \multirow{4}{*}{ Bolsistas } & Mensalidade & 18 & R\$750,00 \\
\hline & Passagem Aérea & 1 & R\$2.000,00 \\
\hline & Custeio & 1 & R\$5.000,00 \\
\hline & Auxilio Instalação & 1 & $\mathbf{R} \$ 500,00$ \\
\hline \multirow[b]{2}{*}{ Coordenadores } & Coordenador Acadêmico & 1 & R\$10.000,00/por ano \\
\hline & Coordenador do Curso de Português & 1 & R\$20.000,00/por ano \\
\hline
\end{tabular}

Fonte: Manual do coordenador do pró-Haiti, 2010, p.6 \& anexo I da portaria nº92, de 28 de abril de 2010.

Analisando esta tabela, descobrimos que os dois coordenadores do programa consumiram a maioria do orçamento do programa ( $\mathrm{R} \$$ $30.000,00 /$ ano), enquanto aos bolsistas receberam uma mixaria para sobreviverem no Brasil, pois desde 2011, o custo de vida tem crescido. Os bolsistas são obrigados ainda a pagar todas as despesas no Brasil, tais como aluguel, comida, roupas, sapatos e outros itens importantes, inclusive cópias, livros, remédios etc. com a mixaria que receberam como bolsa de estudos no país $(\mathrm{R} \$ 750,00)$, somada aos $\mathrm{R} \$ 500$ para o custeio da instalação dos estudantes. Nós, como participantes do Pró-Haiti, na primeira fase do programa conhecido como intercâmbio (2011-2012), não

${ }^{17}$ Conforme o Parágrafo único do Art. $2^{\circ}$. Da Portaria N.092 do Pro-Haiti, este Programa será financiado por meio do recurso de orçamento regular da Diretoria de Relações Internacionais (DRI) da CAPES, podendo ser descentralizado a outros Ministérios ou instituições com vistas a garantir a racionalização de recursos dadas as dificuldades logísticas inerentes a este apoio. Deverá ainda ter caráter emergencial no ano de 2010, podendo ser reestruturado, regularmente, de acordo com as diferentes modalidades do Programa. Os valores utilizados pela CAPES para o financiamento das mobilidades de estudantes são regidos, de acordo com as portarias $\mathrm{n}^{\circ} 92$, de 28 de abril de 2010 e n.206, de 22 de outubro de 2010. 
registramos nenhum momento em que os estudantes foram beneficiados com itens como o valor previsto para custeio $(\mathrm{R} \$ 5.000,00)$. Nesse sentido, não sabemos como foi gasto esse dinheiro.

\section{A SELEÇÃO DOS CANDIDATOS EM 2010-2011}

Como procedimento usual no Brasil, a seleção de candidatos foi realizada por meio de lançamento de um edital. A seleção priorizou candidatos oriundos de áreas como Enfermagem; Medicina; Arquitetura e Urbanismo; Engenharia; Plano para cidade ou Capital e Regional; Ciência Agrária - Agronomia, Conservação de solo; Medicina veterinária e zootecnia, Ciências e Tecnologia para alimentação; Gestão de sistema informatização e ciência informática; Ciências Humanas, entre outras áreas (ver: edital da seleção do pró-Haiti, 2010, p.1, tradução nossa). Para participar na seleção desse programa, os candidatos deveriam preencher as condições seguintes:

Ser cidadão haitiano; 2) Ser estudante em IES haitiana; 3) Não possuir visto permanente ou visto temporário brasileiro; 3.1 É proibida a participação de qualquer cidadão brasileiro, ou cidadão que possua dupla nacionalidade ou mãe ou pai que seja brasileiro. A inscrição no programa pode se realizar em um desses três lugares, seja na Embaixada do Brasil, em Porto príncipe, no Setor de Cooperação Técnica; no Setor Cultural Brasil-Haiti em Porto príncipe; ou no Ministério de Educação Nacional e de Formação Professional - MENFP, mas antes de realizá-la, os candidatos devem comparecer em um desses locais para pegar o formulário, preencher e assiná-lo para poder enviá-la juntos com os documentos exigidos no item 5 desse edital de seleção (EDITAL DA SELEÇÃO DO PRÓ-HAITI, 2010, tradução nossa).

De acordo com o edital, a recepção de candidatos se realizou nos locais mencionados acima, entre 01 e 30 de outubro de 2010. Previa-se a seleção de 200 candidatos, dentre os quais 25 seriam classificados para uma lista de espera da seleção e 175 seriam selecionados e classificados Temáticas, Campinas, 25, (49/50): 233-270, fev/dez. 2017 
em cada uma das etapas da seleção do programa. Essa etapa foi composta de três fases, com caráter eliminatório e classificatório, de acordo com a tradição brasileira na maioria dos processos seletivos, não cabendo recurso em nenhuma das fases dessa seleção. Conforme foi descrito nesse edital, para se candidatar a uma bolsa do Programa Federal de Graduação sanduíche Pró-Haiti, os candidatos deveriam entregar em um dos locais mencionados anteriormente os documentos a seguir:

1. Formulário de inscrição retirado nos locais mencionados acima; 2. Carta de motivação explicando por que manifestou o interesse para o Programa (...); 3. Histórico escolar do curso em andamento em IES haitiano; 4. Um memorial e pelo menos duas cartas de recomendações (...); 5.CV (...) (EDITAL DA SELEÇÃO DO PRÓ-HAITI, 2010, p. 2-3, tradução nossa).

Durante o processo de seleção ocorreu uma denúncia considerada muito grave contra o Ministério da Educação e da Formação Professional - MENFP, no Haiti, acusado de parcialidade na seleção prévia dos candidatos. Esta situação levou a Embaixada brasileira a eliminar as primeiras fases da seleção do programa e abrir uma nova seleção na sede da Instituição, e também ocasionou atraso na publicação do resultado final. De acordo com Thomaz \& Nascimento (2012, p.3), numa irônica coincidência, foram informados que a Embaixada do Brasil recebeu cerca 3.500 inscrições para o programa, que teria sido com isso o maior programa de intercâmbio internacional da história da educação brasileira. Embora a inscrição do programa tenha sido realizada logo após a passagem do terremoto em janeiro de 2010 , constatamos que a publicação dos resultados desse programa demorou um ano e meio, provocando um grande atraso na divulgação das 500 bolsas anunciadas nesse período.

O Brasil publicou os resultados finais da seleção do programa no dia 16 de junho de 2011, via portal CAPES. Foram selecionados apenas 89 candidatos em diversas áreas de conhecimento, mas nesse número de candidatos selecionados pela CAPES não identificamos nenhum 
candidato selecionado na lista de espera, conforme havia sido previsto no edital da seleção do Programa. O número de candidatos selecionados pelo programa ficou distribuído em apenas quatro Universidades: UNICAMP (45); UFSC (32); UFSCAR (7) e UFRGS (5), de acordo com o edital de resultado da seleção programa (2011).

\section{GRÁFICO I- RESULTADOS DO EDITAL DA SELEÇÃO DO PRÓ- HAITI EM 2011}

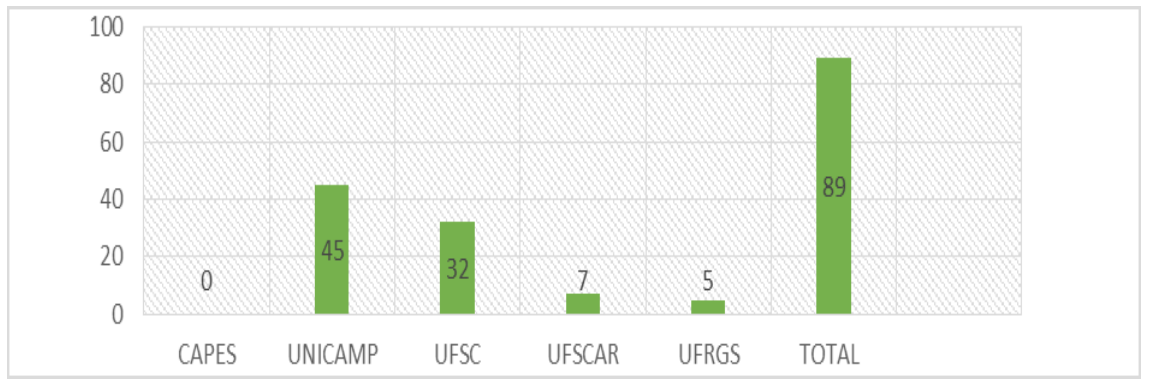

Fonte: Elaborado pelos autores a partir de dados da Capes.

Analisando o resultado final da seleção do programa publicado no site da CAPES, vimos que entre as IES que aderiram ao programa PróHaiti, a UNICAMP se destaca em $1^{\circ}$ lugar, com 45 estudantes, depois a UFSC, com 32, a UFSCAR, com 7 estudantes, e a UFRGS, com apenas 5 estudantes. Nessa perspectiva, podemos dizer que o sucesso desse programa esteve ligado às duas primeiras IES (UNICAMP e UFSC), que ocuparam a pirâmide do Programa no sentido de recebimento do maior número de estudantes em 2011. Conforme o referido edital da seleção, os candidatos selecionados e classificados deveriam entregar os seguintes documentos na Embaixada do Brasil em Porto Príncipe, para retirar os vistos de estudante de tipo item IV com duração de 12 meses e:

Certificado médico físico e mental válido de 90 dias no máximo; Passaporte válido; 2) Certidão de antecedente criminal; 3) Uma taxa de visto, incluindo a taxa para 
legalização dos documentos acadêmicos, como histórico escolar de graduação no Haiti [mais o menos 60 dólares], entre outros documentos que a embaixada poderia solicitar no momento de entrega do pedido de visto de entrada.

Após retirar os vistos de entrada, os selecionados receberiam a passagem aérea de forma eletrônica para que fosse apresentada no aeroporto, onde receberiam o cartão embarque para viagem ao Brasil, o passaporte, visto e outros documentos pessoais válidos, formulário de visto e a carta de concessão de bolsa da CAPES. De acordo com o manual do bolsista (2010), após sua chegada ao país os bolsistas deveriam providenciar, com orientação do coordenador acadêmico, os documentos necessários para o recebimento da bolsa. Além disso, o bolsista deveria observar as seguintes regras:

$\left.1^{\circ}\right)$ Dedicar-se integral e exclusivamente ao desenvolvimento do plano de estudos proposto pelo Coordenador. $2^{\circ}$ ) Solicitar anuência da CAPES para a interrupção das atividades previstas, se plenamente justificada, em casos especiais, com a ciência do coordenador acadêmico; $3^{\circ}$ ) Apresentar relatório final circunstanciado sobre as atividades desenvolvidas, (...); $4^{\circ}$ ) Devolver à CAPES o montante de recursos financeiros recebidos quando do não cumprimento da missão de estudo, conforme avaliação da CAPES. (MANUAL DO BOLSISTA, 2010, p.4).

Por meio desses acordos educacionais, previam-se certas relações entre os dois países. No seu começo, o programa deveria prever a vinda de estudantes, técnicos e professores haitianos para o Brasil, bem como a ida ao Haiti de quadros técnicos, profissionais e acadêmicos brasileiros em distintas fases da sua formação. Contudo, isso não foi possível por conta de falta de recursos (NASCIMENTO \& THOMAZ, 2010). 


\title{
IMPLEMENTAÇÃO E EXECUÇÃO DO PROGRAMA: 2011-2016
}

A viagem dos candidatos selecionados do Pró-Haiti para o Brasil foi realizada no mês de agosto de 2011 com acesso exclusivamente ao visto de estudantes de tipo Item IV, por transporte aéreo em diferentes voos, partindo da capital haitiana, Porto Príncipe-Panamá e conexão aérea de Panamá para São Paulo. Com a chegada dos bolsistas do Pró-Haiti ao Brasil, o Coordenador do programa de graduação-sanduíche, Professor Carlos Roberto Fernandes, deveria encaminhar os seguintes documentos à CAPES:

\begin{abstract}
Cópia do passaporte (incluindo a página com o carimbo de entrada no país); b) Cópia do CPF; c) Cópia do contrato de abertura de conta d) Cópia da reserva da passagem de volta (COORDENADOR DO PRÓ-HAITI, 2010, p.7). (...) Este termo de compromisso datado e assinado; Cópia do histórico de graduação, referente às matérias cursadas semestralmente; Relatório Parcial das atividades exercidas até dezembro de cada ano. Comprovante de matrícula apresentado semestralmente; Cópia anual da renovação do visto; Declaração da Instituição constando o prazo para conclusão do curso, (TERMO DE COMPROMISSO DO PROGRAMA PRÓ-HAITÍ, 2010, p.1).
\end{abstract}

De acordo com a informação encontrada no site da CAPES, publicado no dia de 25 de agosto de 2010, vimos que entre os dias 8 e 10 de agosto, os 76 primeiros bolsistas dos 89 aprovados no Pró-Haiti em Educação Superior chegaram ao Aeroporto Internacional de Guarulhos SP e logo foram direcionados para as respectivas Universidades onde iriam iniciar as atividades do Programa. A UNICAMP recebeu 40 estudantes em seu campus principal, localizado na cidade de Campinas, no Bairro de Barão Geraldo, sendo 29 estudantes, no dia 9 de agosto, e outros 11 estudantes, no dia 11 de agosto de 2011. Dias depois a mesma universidade recebeu mais 1 estudante, somando 41 estudantes dentre os 45 alunos que deveriam ser acolhidos pela universidade. Dos quatro restantes, dois alunos não 
foram localizados no Haiti e dois tiveram problemas com a documentação (SUGUIMOTO; AMORIN; SILVA, 2011).

A UFSC recebeu 24 alunos, dentre os 32 candidatos que deveriam ser acolhidos na Universidade. Além da UNICAMP e da UFSC, a UFSCAR recebeu também 5 estudantes, do total de 7 candidatos selecionados, e que deveriam chegar nos Campi da Universidade no mesmo mês de agosto de 2011, de acordo com notícia publicada no site da UFSCAR em 2011, em nome do Reitor da UFSCAR, Targino de Araújo Filho. A UFRGS, por sua vez, recebeu 8 alunos no âmbito do programa. O número em questão é superior à quantidade estipulada de 5 alunos destinados à UFRGS. O que significa que esta universidade recebeu 3 alunos a mais do que constava no edital do resultado do Pró-Haiti, conforme a notícia publicada na sua página da internet, no dia de 29 de abril de 2015.

Nesta perspectiva, vale apena ressaltar que esses estudantes vêm especialmente para realizar uma graduação "sanduíche" em diversas áreas, com duração de um ano e meio, com seis meses dedicados a um curso de português para estrangeiros, e depois devem cumprir um ano de atividades em disciplinas de seus respectivos cursos nessas instituições. Também estava previsto um curso sobre cultura brasileira, a fim de facilitar a integração dos haitianos à comunidade, algo que não ocorreu nessa rede universitária desde então até os dias atuais.

Qual foi o número de candidatos selecionados do programa PróHaiti que entraram no Brasil e nas IES nesse mês de agosto de 2011? No que se refere aos 89 candidatos selecionados no Programa pela CAPES, Thomaz \& Nascimento (2012) afirmam que não foram mais que 78 estudantes ingressados no Brasil na época para iniciar as atividades do PróHaiti. O motivo apontado é o fato de 11 estudantes selecionados terem tido sua bolsa cancelada ou limitada mesmo antes de virem para o Brasil, sem que o Ministério da Educação - MEC tenha sido capaz de explicar os motivos do ocorrido, nem oferecer quaisquer garantias de continuidade do programa. O número de estudantes que chegaram ao Brasil dentro desse programa pode ser observado nesse gráfico abaixo: 


\section{II- GRÁFICO DE NÚMERO REAL DE ESTUDANTES DO PRÓ-HAITI INGRESSADOS NAS IES BRASILEIRAS E O DE SELECIONADO EM DE 2011}

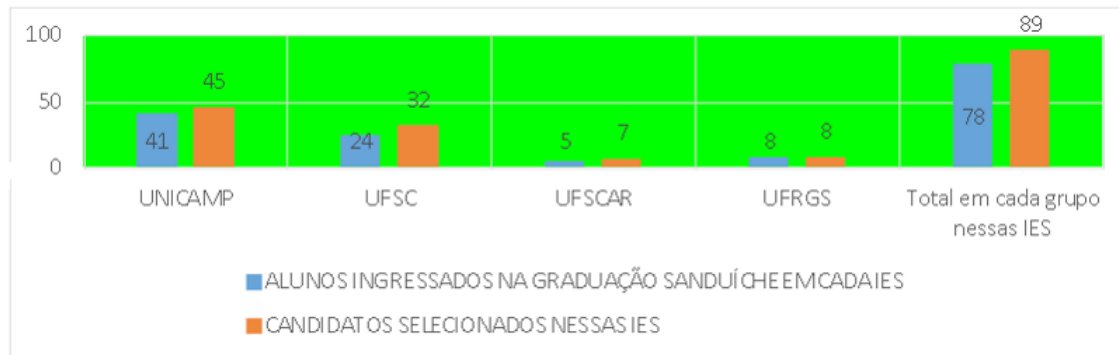

Fonte: Elaborado pelos autores com base de dado da CAPES

As atividades do programa começaram com o curso de português para estrangeiros, com efetivo de 78 de alunos ${ }^{18}$ matriculados no regime de estudantes especiais, em todas as Universidades parceiras do programa no mês de agosto de 2011. O curso deveria ocorrer ao longo de 6 meses, mas teve apenas entre 4 e 5 meses de duração, de agosto a novembro de 2011, mesmo que os alunos não tivessem nenhuma noção da língua portuguesa antes de viajarem para o Brasil, o que indica que passaram por muitas dificuldades com a língua antes de chegar a entendê-la.

Com a conclusão do curso de língua portuguesa nas IES, e após uma série de análises de documentos, os alunos do Programa iniciaram suas atividades acadêmicas. Nesse processo, identificou-se que vários alunos mudaram de área de conhecimento com relação às áreas pelas quais haviam sido selecionados pela CAPES. Sob o estatuto de alunos especiais nessas redes de ensino, a situação pior foi para os alunos que se matricularam nos cursos de Pós-Graduação, uma vez que, de acordo com as normas que regulam esses programas, os estudantes especiais só tinham direitos a cursar de duas a três disciplinas por período letivo em alguns dos programas. Sendo assim, eles se matricularam em disciplinas que podiam cursar nesse regime e conseguiram se adaptar gradativamente,

${ }^{18}$ Além de receber bolsa do governo brasileiro ( $\mathrm{R} \$ 750$ e mais $\mathrm{R} \$ 500$ como valor custeio a instalação), identificamos que quase todos os alunos foram contemplados com bolsas sociais (transporte e alimentação - BAT) no período de 2011- 2012. 
mesmo com muitas dificuldades, demonstrando motivação e disciplina. Tudo isso contribuiu para que os alunos do Programa apresentassem um bom desempenho nas atividades do Programa nas referidas IES. Tais resultados contribuíram muito na implementação de um segundo curso de português, o qual foi chamado "reforço em português", de duração de um semestre, no ano de 2012, para ajudá-los a se adaptar melhor às exigências dos cursos nas IES no Brasil.

As restrições que encontraram nessas IES, devido ao regime de estudante especial, impulsionaram a luta pela transformação do Programa. Elas não foram fáceis, custando um ano de negociações para a aprovação das mudanças por vários atores envolvidos na gestão e com grande participação dos estudantes do Programa. Nesse processo, observamos que as IES parceiras ao programa aproveitaram muito bem os desempenhos dos alunos dessa fase do Programa para convencer os ministérios como MEC, MRE e a CAPES finalizarem o processo de transformação do programa por meio da publicação da Portaria No171, de 06 de dezembro de 2012.

Esse resultado permitiu a regularização legal de todos os alunos do programa. No caso da UNICAMP, houve 36 alunos haitianos que foram regulamente matriculados em março de 2013 e, dentre eles se destacaram 29 nos cursos de graduação e 7 nos cursos de pós-graduação. Identificamos 4 que desistiram, seja no meio das negociações pelas mudanças ou no final dessas negociações com todas as entidades. ${ }^{19}$

Vale destacar que, dentre esse grupo de 7 alunos que ingressaram nos cursos de Pós-Graduação da UNICAMP, identificamos que 2 desistiram

${ }^{19}$ Como Institutos, Faculdades e as Pró-reitorias de Graduação e de Pós-Graduação, bem como a Coordenação das Relações Internacionais (CORI), vinculadas ao Programa por meio da UNICAMP. Houve também o envolvimento da Diretoria de Relações Internacionais (DRI) da CAPES, Embaixada do Haiti no Brasil, Ministério de Relações Exteriores - MRE e da Delegacia da Polícia Federal, conforme esclarece a professora Dra. Eliana Amaral, assessora da Pró-Reitoria de Graduação e responsável do Pró-Haiti. (KÄMPF, 2012). 
do Programa Pró-Haiti por terem sido aprovados também na seleção do PEC-PG de 2012. Em função disso, eles optaram por receber bolsa do PEC-PG em abril de 2013, pois no Brasil é proibido por lei receber duas bolsas de estudos em programas de Pós-Graduação. Assim, o grupo de 7 alunos ficou reduzido a 5. Quanto à realidade dos estudantes do Programa nas universidades federais, como a UFSC, houve a regularização de apenas 17 alunos nos cursos de graduação em 2013, de um total de 24 alunos ingressados nessa IES no regime de estudantes especiais em 2011. A UFRGS regularizou 8 alunos, e a UFSCAR promoveu a regularização de apenas 5 alunos em suas redes de ensino superior. Todos ingressaram exclusivamente nos cursos de graduação, com exceção do caso da Unicamp, em que houve alunos haitianos matriculados na Graduação e na Pós-Graduação, de acordo com o Art. $1^{\circ}$ da Portaria No 171, de 06 de dezembro de 2012, que alterou o item "b" do Anexo I da Portaria n 92/2010. Essa nova realidade do Pró-Haiti nas IES pode ser observada no gráfico a seguir.

\section{Gráfico III - Dados gerais do Pró-Haiti: alunos especiais, regulares e desistentes ou desligados (2011-2013)}

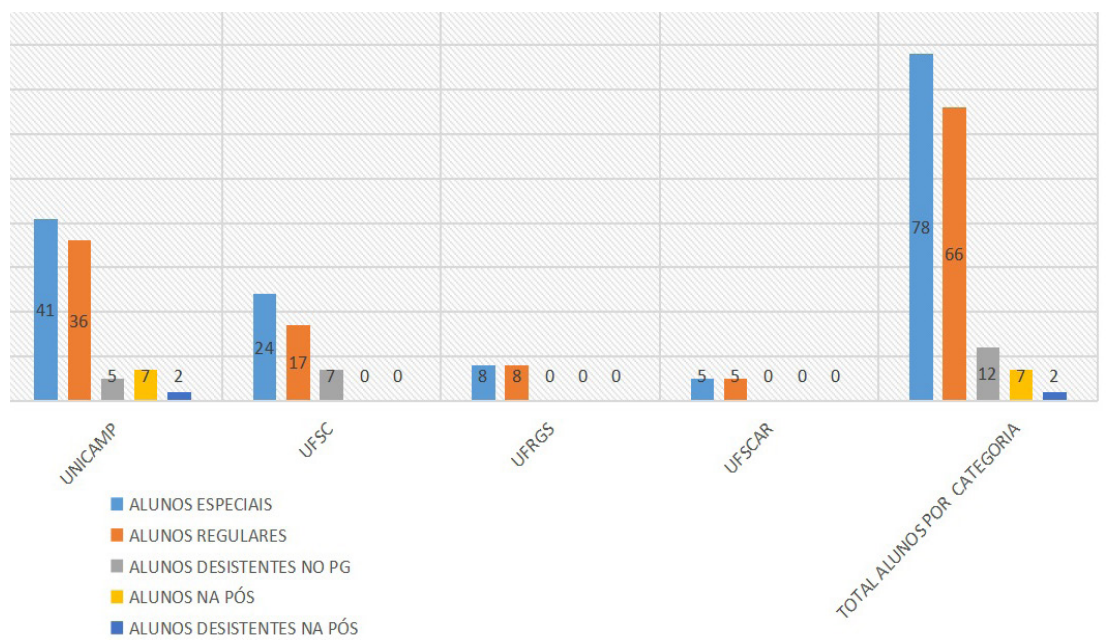

Fonte: Elaborado pelos autores a partir de dados da UNICAMP; UFSC; UFSCAR; UFRGS 
Nesta perspectiva, a vigência do Pró-Haiti passou de 18 para 60 meses. Nesse período, foram incluídos os seis meses de curso português para estrangeiros realizado no período de agosto a dezembro de 2011 afim de que todos os alunos que ingressaram nos cursos de graduação pudessem concluir seus cursos nas Universidades parceiras do programa (ver: anexo I da portaria n.171/2012). Isso quer dizer que os alunos teriam 54 meses para finalizar os seus cursos, com a prorrogação do prazo até 2018. Quase todos os alunos de graduação foram obrigados a recomeçar os cursos nas universidades brasileiras devido a vários procedimentos de análise de documentação realizados entre os anos 2011 e 2012. Esses alunos deveriam retornar ao Haiti imediatamente após o término de seus cursos nessas IES, de acordo com termo de compromisso do programa em 2010; contudo, trata-se de algo que não ocorreu em vários casos de alunos concluintes de seus cursos desde 2015. Constatamos que, além de problemas financeiros, de clima e de racismo enfrentados pelos estudantes do Programa Pró-Haiti no Brasil, destaca-se o fato da maioria dos alunos ter sido obrigada a recomeçar seus estudos nessas universidades apenas no início de 2013, com a transformação definitiva do Pró-Haiti no final de 2012, principalmente com a publicação da referida Portaria de $\mathrm{N}^{\circ}$ 171/2012. A partir daí o estatuto dos estudantes do Pró-Haiti nas IES se transformou completamente, pois passou de graduação sanduíche a graduação plena, o que possibilitou a obtenção de um diploma após o cumprimento de todas as normas exigidas pelas IES brasileiras, de uma bolsa de estudos ${ }^{20}$ garantida até a conclusão de cursos nessas respectivas IES.

\section{EXPOSIÇÃO DE RESULTADOS DO PROGRAMA}

Os resultados alcançados pelo programa no período de 2011 a 2016 mostram que sua implementação ocorreu em dois períodos diferentes

\footnotetext{
${ }^{20}$ Todos eles recebem bolsa-auxílio do governo brasileiro, que varia entre $\mathrm{R} \$ 830$ e $\mathrm{R} \$ 1,5$ mil, de acordo com a CAPES (2013). Além disso, nas Universidades parceiras do Programa, esses alunos têm direito a receber também bolsa de moradia - BM (interna ou externa), transporte e alimentação.
} 
(2011 a 2012, e 2013 a 2016). Esses dois períodos são considerados muito importantes para nossa análise do Programa, tendo em vista que:

$1^{\circ}$ ) o resultado do programa no primeiro período (20112012) foi muito bem sucedido, tanto no curso de português para estrangeiros quanto nas atividades acadêmicas do programa nas universidades parcerias nesse período; $2^{\circ}$ ) no segundo período, de 2013 a 2016, os resultados do Pró-Haiti são resumidos com apenas 34 estudantes que concluíram seus cursos, ou seja, uma porcentagem de $51,5 \%$ dentre os 66 estudantes que permanecem nas IES parceiras (DADOS DAS IES DO PROGRAMA, 2015 \& 2016).

Os egressos do programa são repartidos nessas IES da seguinte forma: 25 alunos, ou seja, uma porcentagem de 73,5\%, (20 na graduação, e 5 na pós-graduação) na UNICAMP, dentre os 51, 5\% de estudantes que concluíram seus cursos nessas IES. Nessa Universidade, identificamos 9 alunos que estão cursando a graduação e uma aluna que desistiu em 2014. No Pró-Haiti, 29 estudantes haviam ingressado nos cursos de graduação, em março de 2013, mesmo que a maioria desses alunos tenha recomeçado os cursos nessa rede (esses dados foram obtidos com colegas haitianos na UNICAMP, em 2016).

Nesse grupo de estudantes concluintes de cursos (Graduação e Pós-Graduação) na Unicamp, principalmente entre os alunos de PósGraduação, constatamos que todos os 5 estudantes concluíram seus respectivos cursos, sendo que 4 deles ${ }^{21}$ receberam notas com conceitos A e B nas avaliações das bancas examinadoras de defesa das dissertações nos respectivos Institutos e Faculdades da UNICAMP. Na UFSC, houve um grupo de 8 alunos que concluiu seus cursos de graduação nos anos de 2013-2016, ou seja, uma porcentagem de 47,5\%, dentre os 17 alunos regulares do Programa nessa universidade em 2013. Além disso, houve

\footnotetext{
${ }^{21}$ Nesse grupo de estudantes, alguns deles do programa na UNICAMP, sejam nos cursos de graduação ou de mestrado, ingressaram nos cursos de mestrado e doutorado na instituição por desejarem continuar estudando no Brasil.
} 
também 3 alunos que desistiram neste grupo de 17 alunos, de acordo com dados repassados pelo responsável pelo Pró-Haiti na UFSC, no dia 11 março de 2016.

Quanto à UFSCAR, identificamos que 5 alunos ingressaram na universidade em 2013, sendo que 1 deles já concluiu seu curso de graduação, ou seja, uma porcentagem de $20 \%$, dentre os 5 alunos que ingressaram nessa IES. Os outros 4 alunos estão com seus cursos em andamento, de acordo com Portal da UFSCAR. Da mesma forma, na UFRGS, identificamos que 8 alunos ingressaram nessa universidade em 2013, mas nenhum deles ainda concluiu seu curso de graduação nesse período. Esses dados podem ser visualizados no gráfico 3 a seguir:

\section{GRÁFICO IV - DADOS SOBRE OS RESULTADOS DO PRÓ - HAITI NAS UNICAMP, UFSC, UFSCAR, UFRGS NO PERÍODO DE 2013- 2016}

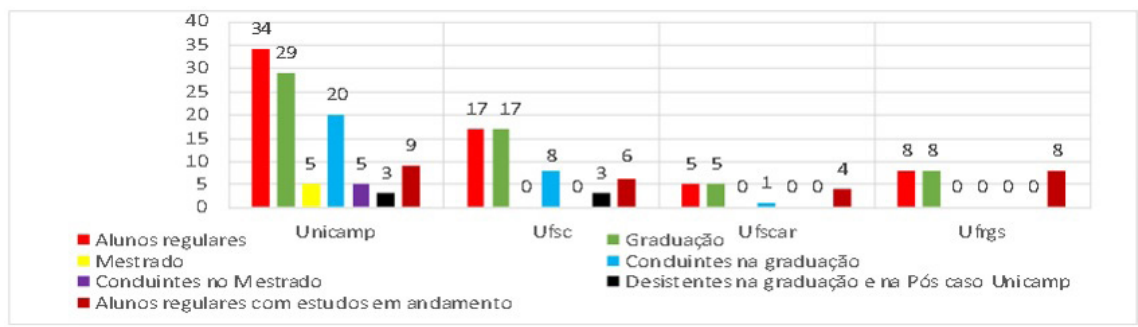

Fonte: Elaborado pelos autores a partir dos dados da UNICAMP; UFSC; UFSCAR; UFRGS

Observando o gráfico acima sobre os dados gerais do Programa, identificamos uma grande disparidade no número de alunos regulares que foram matriculados na UFSC no ano de 2013, quando comparado ao de 2011, quando houve 24 estudantes matriculados haitianos como alunos especiais. Em 2013, por exemplo, identificamos apenas 17 daqueles 24 nessa categoria. Apesar dessa disparidade em relação ao número de alunos que a Universidade deveria ter regularizado, algo que não ocorreu em 2013, vimos que, dentre esses 17 alunos que ingressaram nessa IES, 3 deles desistiram ou tiveram suas bolsas canceladas depois da transformação 
do programa entre 2013 e 2016. Quanto à UNICAMP, a situação foi bem diferente. No ano de 2011, identificamos 41 alunos do programa na categoria de especial, mas com a transformação do programa no final de 2012, houve, em 2013, uma diminuição também neste número de alunos. Assim, a UNICAMP regularizou a situação de 36 alunos em 2013, dentre um total de 41 alunos recebidos em 2011, sendo 5 deles alunos de Pós-Graduação, o que poderia ser vistos como um ponto positivo comparativamente à situação dos alunos na UFSC em 2011 e 2013.

\section{GRÁFICO V - DADOS DE ALUNOS DESISTENTES, ATUAIS, CONCLUINTES DO PRÓ-HAITI NAS UNICAMP, UFSC, UFSCAR, UFRGS NO PERÍODO DE 2013-2016}

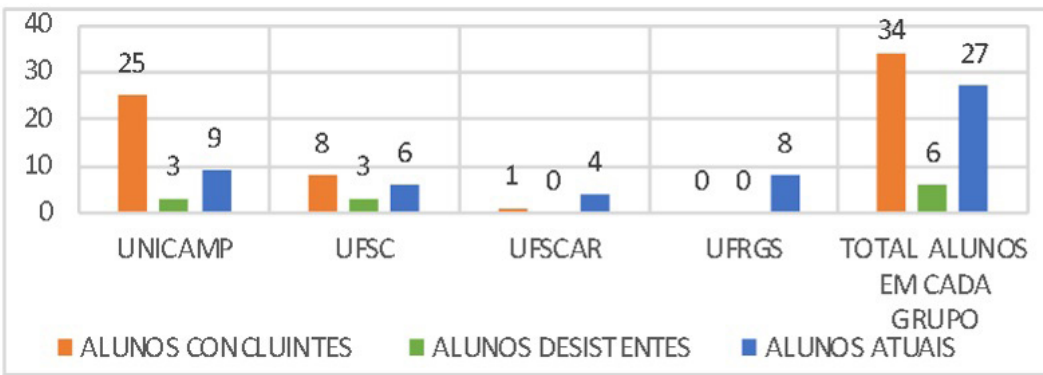

Fonte: Elaborado pelo autor na base do Gráfico IV

Analisando os resultados alcançados pelo Pró-Haiti nas universidades parceiras no período de 2011-2016, vimos que o desempenho do programa foi muito tímido. Há uma disparidade entre os 89 candidatos selecionados em 2011 e o número de 78 candidatos que ingressaram nas IES brasileiras, comparado com a meta do programa, que era de 500 bolsas prometidas pelo Governo brasileiro no período de 2011 a 2016. Verificamos ainda que o programa não realizou mais nenhum processo seletivo para ampliar o número de estudantes ou compensar essa disparidade entre candidatos selecionados e alunos ingressados nas IES parceiras.

Descobrimos também que o número de 78 estudantes que ingressaram nas IES brasileiras em 2011 foi ainda mais reduzido, 
chegando a um número que não ultrapassou 60 entre 2013-2016. No período de 2011 a 2016, identificamos 18 alunos que desistiram dos cursos ou tiveram suas bolsas canceladas nas duas IES, sendo 12 alunos especiais nos anos de 2011 e 2012, e mais 6 alunos regulares nos anos de 2013 a 2016. Considerando o objetivo do programa, que é contribuir para a reconstrução do Haiti por meio do apoio à formação de recursos humanos e à reestruturação das instituições de ensino superior haitianas, tal programa não chegou a contemplar números razoáveis de estudantes para gerar resultados suficientes para atingir esse objetivo, uma vez que houve um número muito grande de alunos desistentes ao longo desse período estudado.

No caso da UFSC, havia inicialmente 24 alunos ingressados em 2011 no regime de estudantes especiais, dentre os 32 candidatos selecionados nessa instituição no mesmo ano. Este número foi reduzido a 17 alunos regulares em março de 2013, em virtude da desistência ou cancelamento de bolsas entre 2011-2012. No período de 2013 a 2016, também foi possível identificar 3 alunos regulares que desistiram ou tiveram suas bolsas canceladas, de um total de 17 alunos regulares do Programa na UFSC desde 2013.

$\mathrm{Na}$ Unicamp, no entanto, a situação foi menos grave porque dentre os 41 estudantes ingressantes em 2011, 36 deles foram regularizados em 2013, e 3 desistiram entre 2013 e 2015. E o número de alunos desistentes foi de 14 e 33, respectivamente, na UFSC e na UNICAMP (GRÁFICO III; IV; V). Nas outras universidades, como UFSCAR e UFRGS, não houve nenhum caso de desistência de alunos no ano de 2011 devido à configuração do Programa e ao número de alunos recebidos nessas instituições.

O programa não chegou a selecionar nem 100 alunos para as 500 bolsas prometidas. Assim, chegamos à conclusão de que esse tipo de Programa não vai realizar a tão prometida melhoria na Educação Superior haitiana, pois em vez de ajudar o sistema de ensino superior do país caribenho, conforme descrito em todos os documentos analisados, verificamos que o Brasil se comportou desde 2004 como um país subimperialista na sua relação com o Haiti. O que se percebe é que o Brasil 
tem buscado se aproveitar das crises ou momentos difíceis do Haiti para fazer todos os tipos de negócios no país, seja por meio de suas diversas ONGs, seja por meio de seu exército integrante e líder da MINUSTAH, desde 2004, no país.

A ampliação das ações brasileiras no Haiti se dá por meio de falsas propagandas ou promessas não cumpridas, com o início do processo migratório haitiano para o Brasil em 2010, bem como o Pró-Haiti e juntando com a migração haitiana iniciada naquele mesmo ano. Em relação a isso, Thomaz \& Nascimento (2012, p.2) afirmam que logo após o terremoto, e apoiando-se numa opinião pública francamente solidária, o governo brasileiro havia anunciado projetos ambiciosos de intercâmbio e formação de quadros haitianos em áreas estratégicas, como a saúde e a educação, para os quais dotações orçamentárias foram rapidamente aprovadas. No entanto, os autores afirmam também que esses projetos nunca chegaram a ser executados, além de dirigirem outras críticas à atuação e à postura do governo brasileiro diante dos problemas do Haiti. Implicitamente, fica a sensação do conhecimento de causa e de levantamento de informações para sustentar as situações abordadas por eles:

Também na área da saúde, havia sido anunciada a construção de dez Unidades de Pronto Atendimento em Porto Príncipe, dotadas de anexos para a formação de agentes comunitários. Deveriam entrar em funcionamento ainda em 2010. Nenhuma sequer foi construída e apenas uma equipe haitiana formada por um médico e duas enfermeiras esforça-se por atuar sem sede definida. (...) (THOMAZ \& NASCIMENTO, 2012, p.3).

Se tais alegações são verdadeiras, seria válida a crítica de que esses projetos iniciais serviram principalmente para dar imensa visibilidade ao governo brasileiro, blindando a opinião pública com informações fiáveis e negando aos haitianos a possibilidade de falarem por si (THOMAZ \& NASCIMENTO, 2012, p.3). Vimos que desde 2010 o Programa Pró-Haiti contribuiu muito no incentivo ao processo de transformação do Haiti em 
laboratório ${ }^{22}$ de pesquisa, algo iniciado no país desde 2004. Tal processo faz com que os participantes (estagiários ou pesquisadores) vindos de todas as partes do mundo pudessem entrar no país para realizar quaisquer tipos de pesquisa e publicarem quaisquer coisas sem ter o mínimo de respeito em relação ao povo haitiano. Nesse esquema, o Brasil encontra-se muito bem inserido por meio da MINUSTAH, suas ONGs, do processo migratório haitiano do Pró-Haiti através de um volume de projetos de pesquisas financiados pelo Brasil nas suas IES. Esse volume de projetos nos programas de Pós-Graduação é desenvolvido por estudantes ou docentes brasileiros, sendo que a maioria dos estagiários ${ }^{23}$ não possuem nenhum tipo de experiência na área de pesquisa. Para grande parte do povo haitiano, esse tipo de dominação é uma vergonha para o país.

Assim, finalizando este trabalho, afirmamos que o Brasil não cumpriu e não vai cumprir essa promessa e que, por isso, ele não contribuiria também na reconstrução do Haiti por meio desse programa. Os resultados do programa deixaram muito claro que ele foi inserido apenas como uma das ações brasileiras visando a reforçar os negócios brasileiros no Haiti a partir de 2004. Tal programa incentivou também a campanha internacional iniciada pelo Brasil há muito tempo, cujo objetivo é conseguir uma vaga no Conselho de Segurança Permanente da ONU. Por isso, sua candidatura foi apresentada ao Conselho Superior das Nações Unidas (CSONU) entre os anos 2010 e 2011, tendo em vista atingir o objetivo de permanecer no comando das tropas da Missão das Nações Unidas para a Estabilização no

${ }^{22}$ Em sua denúncia, o professor brasileiro Ricardo Seitenfus, então Representante Especial do Secretário Geral da OEA e Chefe do Escritório da mesma instituição no Haiti em 2010, pinta o quadro sem meias-palavras: "O país oferece um campo livre para todas as experiências humanitárias. É inaceitável do ponto de vista moral considerar o Haiti como um laboratório. $A$ reconstrução do Haiti e a promessa de 11 bilhões de dólares que fazemos brilhar inflamam muitos interesses. Parece que um monte de gente veio ao Haiti, não para o Haiti, mas para fazer negócios" (ROBERT, 2010; grifos nossos). Essa oportunidade de fazer negócios tem sido ainda reforçada pela bactéria de cólera importada pela ONU através do contingente militar nepalês da MINUSTAH e diagnosticada 9 meses depois do terremoto, no dia 19 de outubro de 2010. Em pouco tempo, ela se espalhou por todo o território haitiano (KLARREICH; POLMAN, 2012).

${ }^{23}$ A CAPES poderá, de acordo com os projetos apresentados, conceder bolsas de estágio à docência a alunos de pós-graduação, de acordo com suas normas (ANEXO I DA PORTARIA N.092, 2010).

Temáticas, Campinas, 25, (49/50): 233-270, fev/dez. 2017 
Haiti - MINUSTAH, a qual o Brasil liderou desde 2004 até final de 2017, além de ampliar sua pasta de políticas externas de cunho subimperialista na região.

O Haiti apresentara-se como uma vitrine do savoir-faire (saber-fazer) brasileiro, e por isso denotava importância estratégica (VÉRAN; NOAL; FAINSTAT, 2014). Nessa perspectiva, o posicionamento do governo brasileiro no processo de recolonização do Haiti por meio da MINUSTAH a partir de 2004, do Pró-Haiti, bem como do processo migratório haitiano para seu território desde 2010, visa apenas priorizar a possibilidade de aumentar a reputação internacional do Brasil. Tudo isso acabou elevando a projeção de poder econômico e político do país, contribuindo para garantir o seu peso regional na América Latina, a sua presença em assuntos militares e econômicos internacionais (BRACEY, 2011).

A respeito do processo de recolonização do Haiti, Franck Seguy afirmou que tal projeto já ficava claro no texto do "Plano de Ação para a Recuperação e o Desenvolvimento o Haiti” (PARDN), apresentado pelo governo haitiano dois meses depois do terremoto. O governo haitiano escreveu um plano de reconstrução que ele apresenta aos seus parceiros da chamada comunidade internacional, e não à sociedade civil haitiana (SEGUY, 2014). Segundo o pesquisador, esse plano foi apenas uma versão atualizada de um estudo realizado por um economista da Universidade de Oxford, Paul Collier, que foi enviado ao Haiti pelo Secretário Geral da ONU, tendo publicado seu relatório em janeiro de 2009. Assim, podemos dizer o que está sendo implementado hoje no Haiti, como 'reconstrução', na verdade é um plano anterior ao terremoto (SEGUY, 2014).

\section{CONSIDERAÇÕES FINAIS}

Considerando que a educação é, sem dúvida, uma atividade fundamental em qualquer sociedade, entendemos que ela é tida como um dos fatores de desenvolvimento socioeconômico e também um dos componentes fundamentais para o desenvolvimento sociocultural, político e econômico de cidadãos e da sociedade (ALPHONSE, 2015, p.1 apud DELORS, 1996). Considerando também que durante o último século o 
mundo conheceu um desenvolvimento econômico sem precedentes, estes avanços se devem, em grande parte, à ciência e à educação. Nesse sentido, é patente a necessidade de redefinir a educação não apenas na perspectiva dos seus efeitos sobre o crescimento econômico, mas com uma visão mais ampla sobre o desenvolvimento humano (ALPHONSE, 2015, p.1 apud DELORS, 1996).

Partindo desse pressuposto, Frigotto (2000) reafirma que o ensino superior, assim como a escola, é visto como um dos motores de desenvolvimento econômico. Para esse autor, essa ideia foi e é amplamente disseminada como a "panaceia" para solucionar os problemas das desigualdades existentes entre os países e os indivíduos, "mediante os organismos internacionais como (BID, BIRD, OIT, UNESCO, FMI, USAID, UNICEF) e os organismos regionais (CEPAL e CINTEFOR), que representam dominantemente a visão e os interesses do capitalismo integrado ao grande capital" (ALPHONSE 2015, p.1 apud FRIGOTTO, 2000).

Comparando os objetivos e metas com os resultados efetivos alcançados pelo Pró-Haiti no período analisado, vimos que existe uma distância muito grande entre esses três componentes. Além disso, pode-se perguntar: se os resultados alcançados pelo programa são muitos tímidos, por que a CAPES não lançou nenhum novo edital para ampliar o número de alunos haitianos nas universidades públicas brasileiras para melhorar o desempenho do programa nessas Universidades no sentido de cumprir a promessa? Por outro lado, conforme indicado acima, o referido programa contribuiu apenas com o incentivo da transformação do Haiti em um laboratório de pesquisa para os pesquisadores e estagiários brasileiros realizarem suas pesquisas.

Concluímos afirmando que o Brasil não cumpriu e não irá cumprir a promessa e que, portanto, ele não contribuirá para a reconstrução do Haiti através desse programa. Por isso, enquanto as autoridades haitianas não tomarem consciência disso e romperem com as práticas que o Haiti mantém com países subimperialistas para passarem a investir adequadamente no sistema de educação do país, nenhuma recuperação será possível. 


\section{REFERÊNCIAS BIBLIOGRÁFICAS}

ALPHONSE, Fritznel. Análise do Programa de Ação Afirmativa e Inclusão Social (PAAIS) implementado pela UNICAMP no período de 2005-2014. Dissertação de Mestrado, Faculdade de Educação da Universidade Estadual de Campinas, Campinas, SP, 2015.

ANGLADE, Georges. Espace et liberté en Haïti. Montréal: ERCE, 1982.

BRACEY, Djuan. O Brasil e as Operações de Manutenção da Paz da ONU: os casos do Timor Leste e Haiti. Contexto Internacional, v. 33, $\mathrm{n}^{\circ}$ 2, 2011. Disponível em: <http://funag.gov.br/loja/download/375Brasil_e_a_Crise_Hatiana_O.pdf>. Acesso em 10/03/2016.

BRASIL, MEC. Edital Pwogram Dijans Pró-Haiti ke Ministè Edikasyon brezilyèn fépou etidyan ayisyen ki vle gen lisans, S/d.. Disponível em: < http:/ / www. sistemas. mre.gov.br/kitweb/datafiles/PortoPrincipe/pt.../Dekrè. doc $>$. Acesso em: 15/08/2011.

BUENO, Fábio; SEABRA, Raphael. A teoria do subimperialismo brasileiro. In: América Latina em movimento [online], 2009.

CONGRÈS MONDIAL HAÏTIEN. Cahier nº 1. Janvier, Montréal. 2005.

COORDENAÇÃO DE APERFEIÇOAMENTO DE PESSOAL DE NÍVEL SUPERIOR - CAPES. ANEXO I DA PORTARLA N.171, DE 06 DE DEZEMBRO DE 2012. Disponível em: < http://www. capes.gov.br/images/stories/download/bolsas/AnexoI-ProHaiti12dez12.pdf>. Acesso em: 10/12/2012.

__ Estudantes aprovados no Pró-Haiti chegam ao Brasil, 2011. Disponível em:<http:/ / www.capes.gov.br/sala-de-imprensa/noticias / 4827 estudantes-aprovados-no-pro-haiti-chegam-ao-brasil $\geq$. Acesso em: 30/08/2011.

Manual de Orientações para Bolsistas. Programa Pró-Haiti, 2011. Disponível em: <http://www.capes.gov.br/images/stories/download/bolsas/ ProHaiti_ManualDoBolsista.pdf $>$. Acesso em: 01/03/2011. 
Manual de Orientações Técnico-Financeiras do Programa Pró-Haiti, 2010. Disponívelem:<http://www.capes.gov.br/images/stories/ download/bolsas/ProHaiti_ManualDoCoordenador.pdf $>$. Acesso em: 30/10/2010.

PORTARIA No 171, DE 06 DE DEZEMBRO DE 2012. Disponível em:<http://www.capes.gov.br/images/stories/download/ legislacao/Portaria171-6dez12_HAITI.pdf $>$. Acesso em: 10/08/2012.

Manual do Programa de Estudantes-Convênio de Pós-Graduação - PEC-PG. Brasília, Brasil, 2008. Disponível em:<https://www.capes.gov.br/ images/stories/download/bolsas/Manual_PECPG.pdf>. Acesso em: 8/08/2016.

PORTARIA N $N^{\circ}$ 092, DE 28 DE ABRIL DE 2010. Institui o Programa Emergencial PRÓ- HAITI em Educação Superior dispõe sobre os procedimentos para operacionalização das atividades do programa, publicada no DOU no dia 29 de abril de 2010, sessão 1, pp. 22/23. Disponível em: <http://www.capes.gov.br/images/ stories/download/legislacao/Portaria09228abr2010_ProHAITI_ AlterPort-171-2012.pdf>. Acesso em: 20/08/2011.

PORTARIA No 171, DE 06 DE DEZEMBRO DE 2012, 2012 ALTERA A PORTARIA No 92, DE 27 DE ABRIL DE 2010. Disponível em: <http://www.capes.gov.br/images/stories/ download/legislacao/Portaria171-6dez12_HAITI.pdf > . Acesso em 10/12/2012.

PORTARIA No. 206, DE 22 DE OUTUBRO DE 2010, publicado no DOU, No 204, segunda-feira, 25 de outubro de 2010. Disponível em: $<$ http://www.capes.gov.br/images/stories/download/legislacao/ Portaria09.pdf $>$. Acesso em: 30/10/2010.

Resultado Programa Emergencial Pró-Haiti. Disponível em: <http:// www.capes.gov.br/images/stories/download/editais/resultados/ Resultado_ProHaiti_16jun11.pdf>. Acesso: em 20/06/2010. 
CHADE, Jamil. Soldados brasileiros são acusados de abusos sexuais no Haiti, diz agência de notícias. In: O Estado de São Paulo, 2017. Disponível em: <http://internacional.estadao.com.br/noticias/ geral,soldados-brasileiros-sao-acusados-de-abusos-sexuais-no-haitidiz-agencia-de-noticias,70001741751>. Acesso em: 11/01/2018.

COLLIER, Paul. "Haïti: des catastrophes naturelles à la sécurité économique". In : Rapport au Secrétaire général de l'Organisation des Nations Unies, 2009. Disponível em: <http://www.haitimonde.com/ capsules/IMG/pdf/Collier_Rapport_sur_Haiti.pdf $>$. Acesso em: 22/01/2010.

DELORS, Jacques Educação: Um Tesouro a Descobrir. Relatório para a UNESCO da Comissão Internacional sobre Educação para o Século XXI. Paris/Porto: UNESCO/ASA, 1996.

FRIGOTTO, Gaudência. Educação e crise do capitalismo real. São Paulo: Cortez, 2000.

HAITI. Plan d'action pour le relèvement et le développement national d'Haïti, les grands chantiers pour l'avenir, 2010. Disponível em: whc. unesco.org/ document/106590. Acesso em: 24/03/ 2015.

KÄMPF, Cristiane. Unicamp regulariza situação de 36 alunos haitianos na graduação e na pós, 2012. Disponível em: <http://www.unicamp.br/unicamp/ noticias/2012/12/21/unicamp-regulariza-situacao-de-36-alunos-haitianosna graduacao-e-na-pos>. Acesso em: 01/03/2013.

KATZ, Claudio. America Latina frente a la crisis global, 2009. Disponível em: <http://www.lahaine.org/katz/>. Acesso em: 12/01/2017.

KLARREICH, Kathie \& POLMAN, Linda. The NGO Republic of Haiti, 2012. Disponível em: <https://www.thenation.com/article/ngorepublic-haiti/>. Acesso em : 15/03/ 2015.

LOUIS-JUSTE, Jal. A. Université et Citoyenneté en Haïti. Disponível em: $\quad<$ http://www.alterpresse.org/spip.php?article798\#. Utx99LTJ1LM>. Acesso em: 08/03/2017. 
Internacional Comunitária: ONGs chamadas alternativas e Projeto de livre individualidade Crítica à parceria enquanto forma de solidariedade de espetáculo no Desenvolvimento de comunidade no Haiti. Tese (Doutorado em Serviço Social). Universidade Federal de Pernambuco, 2007. Disponível em: https://repositorio. ufpe.br/bitstream/handle/123456789/9571/arquivo8293_1. pdf? sequence $=1 \&$ is Allowed $=\mathrm{y}$. Acesso em: 10/03/2015.

LUCE, Mathias. S. O subimperialismo brasileiro revisitado: a política de integração regional do governo Lula (2003-2007). Dissertação de Mestrado, Universidade Federal do Rio Grande do Sul. Instituto de Filosofia e Ciências Humanas. Programa de Pós-Graduação em Relações Internacionais, 2008.

MINISTERE DA EDUCAÇÃO/MINISTERIO DAS RELAÇÕES EXTERIORES - MEC/MRE. Manual do Programa de EstudantesConvênios de Graduação. Brasília: Ministério da Educação, Secretaria de Educação Superior/Ministério das Relações Exteriores, Divisão de Cooperação Educacional, 2004.

NATIONAL HUMAN RIGHTS DEFENSE NETWORK. RNDDH condemns the involvement of MINUSTAH agents in yet another violation of buman rights, 2011. Disponível em: <https://www.alainet.org/ images/Rapport $\% 20$ RNDDH $\% 20$ sur $\% 201 \mathrm{a} \% 20$ MINUSTAH. pdf>. Acesso em 12/03/ 2018.

MARINI, Ruy. Mauro. "La acumulación capitalista mundial y el subimperialismo". In: Cuadernos Políticos, n. 12, Ediciones. Era, México, 1977. América Latina: integração e dependência. São Paulo: Brasil Urgente, 1992. Subdesarolo y Revolución. Buenos Aires: Siglo XXI, 1974.

MILFORT, Milo. Les Bébés Minustah en Haitt: La partie immergée d'un iceberg d'exploitation et abus sexuels! Une enquête réalisée par ENQUET'ACTION, 2017. Disponível em: < https://haitiliberte.com/les-bebes-minustah- 
en-haiti-la-partie-immergee-dun-iceberg dexploitation-et-abussexuels/>. Acesso em 15/01/2018.

MORNEAU, Jacques. Reflections on the situation in Haiti and the ongoing UN mission. In: SHAMSIE, Yasmine; THOMPSON, Andrew S. (Eds.). Haiti: hope for a fragile state. Waterloo. Wilfrid Laurier University Press, 2006.

PIARROUX, Renaud. Rapport de mission sur l'épidémie de choléra en Haïti, 2010. Disponível em: <http://medias.lemonde.fr/mmpub/edt/ doc/20101210/1452027_1b80_cholera_haiti_rapport_pr_piarroux. pdf $>$. Acesso em 10/03/2015.

ROBERT, Arnould. Haïti est la prewve de l'échec de l'aide internationale, 2010. Disponível em: <http://www.letemps.ch/Page/ Uuid/2a1b8ad0-0bb8 11e091f44e4896afb502/Ha\%C3\%AFti_est_ la_preuve_de_1\%C3\%A9chec_de_laide_internationale $>$.Acesso em 20/07/2016.

SEGUY, Franck. A catástrofe de janeiro de 2010, a "Internacional Comunitária" e a recolonização do Haiti. Tese (Doutorado em Sociologia) - Universidade Estadual de Campinas, Instituto de Filosofia e Ciências Humanas. Campinas, 2014.

Racismo e Desumanização no Haiti, Educere et Educare. Revista de Educação: Educere et Educare, UNIOSTE, Cascavel, v.10, n.20, 2015. Disponível em: <http://e-revista.unioeste.br/index.php/ educereeteducare/article/view/12594/9008>. Acesso em: 10/03/ 2016.

SEITENFUS, Ricardo. Elementos para uma diplomacia solidária: a crise haitiana e os desafios da ordem internacional contemporânea, 2006. Disponível em: $<$ http://www.seitenfus.com.br/arquivos/elementos-diplomacia(1). pdf $>$ jun. 2014. Acesso em: $10 / 05 / 2016$.

SUGIMOTO, Luiz. Já chegaram ao campus 40 estudantes do Programa Emergencial PróHaiti, Unicamp, 2011. Disponível em: < http://www.unicamp.br/unicamp/ 
noticias $/ \mathrm{j} \% \mathrm{C} 3 \% \mathrm{~A} 1$-chegaram-ao-campus-40-estudantes-do-programaemergencial-pr\%oC3\%B3-haiti>. Acesso em 11/08/ 2011.

THOMAZ, Omar; NASCIMENTO, Sebastian. Fronteira social e fronteira de serviço. O Estado de S. Paulo, 2012. Disponível em: <http:/ /www. estadao.com.br/noticias/suplementos, fronteira-social-e-fronteiradeservico, 828430,0.htm>. Acesso em: 15/06/2013.

VALLER FILHO, Waldimir. O Brasile a crise haitiana: a cooperação técnica como instrumento de solidariedade e de ação diplomática. Brasília: Instituto Rio Branco, Fundação Alexandre Gusmão- Ministério das Relações Exteriores, Fundação Biblioteca Nacional, 2007. Disponível em: funag.gov.br/loja/download/375-Brasil_e_a_Crise_Hatiana_O. pdf. Acesso em 15/03/2015.

VIEIRA, Ana. Luisa. Abusos e violência: tropas chefiadas pelo Brasil no Haiti são criticadas, 2017. Disponível em :<https://noticias.r7.com/ internacional/abusos-e-violencia-tropas-chefiadas-pelo-brasil-nohaiti-sao-criticadas-24102017>. Acesso em 10/01/2018.

WAISBICH, Laura. \& POMEROY, Melissa. Haiti. Um laboratório de engajamento multisetorial. Observatório Brasil e do Sul. Perspectivas de Território (informativo), 2014. 
